\title{
ÉTICA DA CRENÇA, FAKE NEWS E RESPONSABILIDADE
}

Felipe Rocha Lima Santos ${ }^{1}$

\begin{abstract}
RESUMO
Este artigo tem como objetivo discutir a ética da crença e as relações entre responsabilidade epistêmica e responsabilidade moral, para ao final, aplicar a discussão a avaliação de casos que envolvem o uso das redes sociais para obter fake news e compartilhar as mesmas. Para atingir este objetivo, irei inicialmente discutir a norma da ética da crença de Clifford, na primeira seção, para assim, na segunda seção, criticar a ideia de correlação entre responsabilidade epistêmica e moral defendida por Clifford. Na terceira seção apresentarei a teoria dos vícios epistêmicos de Cassam, para assim, na seção final, avaliar casos que envolvem fake news e redes sociais sob a perspectiva de vícios epistêmicos. Fecharei o artigo com uma breve discussão sobre os riscos de se propor sem discussão adequada leis que buscam criminalizar as fake news.
\end{abstract}

Palavras-chave: Ética da Crença. Normatividade Epistêmica. Vícios Epistêmicos. Responsabilidade Epistêmica. Fake News.

\begin{abstract}
This paper aims to discuss the ethics of belief and the relationship between epistemic responsibility and moral responsibility, in order to apply the discussion to the evaluation of cases involving the use of social media to obtain fake news and share them. To achieve this goal, I will first discuss the norms of Clifford's ethics of belief in the first section, and thus, in the second section, criticize the idea of the correlation between epistemic and moral responsibility advocated by Clifford. In the third section I will present Cassam's theory of epistemic vices, so that, in the final section, evaluate cases involving fake news and social media from the perspective of epistemic vices. I will close the paper with a brief discussion of the risks of proposing laws that seek to criminalize fake news without proper discussion.
\end{abstract}

Keywords: Ethics of Belief. Epistemic Normativity; Epistemic Vices; Epistemic Responsibilities; Fake News.

${ }^{1}$ Pesquisador pós-doutoral no PPG-F da UFBA. E-mail: frlsba@gmail.com. 


\section{Introdução}

O objetivo deste texto é o de discutir certos aspectos da discussão sobre a ética da crença e responsabilidade, para assim poder aplicar ao contexto das chamadas fake news, conhecendo um pouco sobre a sua estrutura em que estão envolvidas, desde a criação das fake news como armas de estratégias de propaganda política a seu "curso de vida" ordinário, ou seja, a distribuição destas fake news, como elas chegam nas pessoas e como as pessoas acabam acreditando e compartilhando as mesmas. Neste sentido, pretendo discutir aspectos da responsabilidade das pessoas comuns que recebem as notícias, acreditam nelas e compartilham as mesmas, além de discutir a responsabilidade dos criadores e outros atores envolvidos nesta estrutura. Será irresponsável ou digno de culpa compartilhar fake news? Qual tipo de responsabilidade está em jogo nestes casos, apenas responsabilidade epistêmica ou também responsabilidade moral? Após esta discussão, pretendo muito brevemente demonstrar que existe um risco grande de erro nas tentativas descuidadas de elaborar e aprovar leis que supostamente deveriam combater as fake news, e que por isso, a contribuição da filosofia para esta discussão, como busco demonstrar com este texto, é fundamental.

Antes de começar a discussão, acredito que vale a pena chamar atenção para o que acontece na nossa vida, no que diz respeito a este tema. Neste contexto e na nossa vida ordinária, é muito comum ver pessoas acusando outras: "Como é possível que você acredite nisso? Está claro que isso é falso!"; "Você é irresponsável por ter compartilhado esta mentira. Está tão claro que é uma mentira que você sabe disso e fez isso propositadamente!". As acusações são tantas acusações de cunho moral como de cunho epistêmico. E, para os que acusam, parece ser muito óbvio, explicitamente claro que o acusado está atuando de modo incorreto e irresponsável. O curioso é que ambos os lados de certa divisão política acusam igualmente o outro lado dos mesmos erros. E o uso de fake news como estratégia de manipulação tampouco é exclusivo de um lado da discussão, seja este lado a esquerda, extrema esquerda, direita ou extrema direita ${ }^{2}$.

\footnotetext{
${ }^{2}$ Quero uma vez mais enfatizar que dentro das divisões políticas brasileiras, direita/esquerda, há tanto as mesmas acusações de que o outro crê de modo irresponsável e imoral como há também o uso do que chamamos de fake News em ambos os lados. Ou seja, nada do que será discutido neste texto é válido apenas para os que são de direita ou de esquerda, mas
} 
Entretanto, o fenômeno das fake news não é algo novo e igualmente suas consequências perigosas já são bastante conhecidas. Um dos casos mais paradigmáticos no Brasil foi o caso da Escola Base, que ocorreu em uma época onde não existiam redes sociais ${ }^{3}$. Apesar de não ser um caso estrito de fake news (nas seções quatro definirei melhor o que é fake news), este é um caso que demonstra o poder destrutivo de notícias falsas na vida das pessoas. Neste caso, os diretores da Escola Base foram falsamente acusados de pedofilia. Os meios de comunicação passaram a noticiar o caso de modo parcial, e os envolvidos na investigação, por conta da pressão social e midiática, cometeram uma série de erros. Os acusados foram depois inocentados, mesmo tendo a vida completamente destruídas por este caso e praticamente impossível de ser recuperada. E muitos dos meios de comunicação foram processados e tiveram que pagar indenizações altas para as vítimas das falsas acusações. Este exemplo, por si mesmo, já é capaz de demonstrar o poder destrutivo de falsidades na vida das pessoas. Outro exemplo já mais recente, ocorreu por conta de boatos ${ }^{4}$ em redes sociais. Em maio de 2014, Fabiane de Jesus saiu de sua casa com sua Bíblia na mão para comprar frutas. Depois de comprar frutas, ofereceu uma das frutas a um menino que estava na rua, e a mãe do menino viu. Ela viu Fabiane e associou a mesma ao boato que circulava nos grupos de Whatsapp e redes sociais sobre uma mulher que sequestrava crianças para rituais satânicos. Esta confusão foi o suficiente para que Fabiane fosse linchada e assassinada em plena luz do dia por mais de 100 pessoas. Tudo por conta de um boato, uma mentira, compartilhada nas redes sociais.

Talvez por conhecermos o real poder da mentira divulgada tanto pelos meios de comunicação como pelas redes sociais na vida das pessoas nos dá convicção de que estamos corretos ao acusar aqueles que acreditam e compartilham as fake news de epistemicamente como moralmente irresponsáveis. E esta talvez seja uma boa motivação para justificar a criação de leis

sim, é valido igualmente para qualquer lado político.

${ }^{3}$ Este caso foi tão paradigmático no Brasil que passou a ser estudado em praticamente todos os cursos de comunicação e jornalismo. Um livro recente foi publicado sobre este tema, fazendo uma análise mais crítica e detalhada de todos os erros cometidos pelos personagens envolvidos na época, principalmente a imprensa. Ver COUTINHO (2016).

${ }^{4} \mathrm{Na}$ seção quatro apresentarei uma breve diferença entre boato e fake news, mas o que é relevante saber é que ambos possuem a capacidade de contaminar nosso ambiente informacional e de causar dano a pessoas. 
que tornam um crime o compartilhamento de fake news. Entretanto, sabemos que nem tudo é tão simples. Uma pessoa que recebe uma informação de outra pessoa que é supostamente confiável, um advogado, um médico, ou mesmo a fala de um ganhador de um prêmio Nobel, realmente é culpada por acreditar de fontes que tem tudo para serem consideradas fontes confiáveis? Esta pessoa deveria ser legalmente punida por ter acreditado e compartilhado o que recebe de fontes que considera confiáveis? Espero que a discussão deste artigo traga luz sobre estes problemas e nos ajude a refletir, desde a perspectiva da epistemologia, o que está por detrás destas questões.

Este texto está estruturado da seguinte maneira: na primeira seção pretendo resgatar um pouco da discussão clássica sobre a Ética da Crença, em especial a discussão centrada no texto de Clifford, para definir um aspecto fundamental das acusações tanto epistêmicas como morais sobre como cremos e como compartilhamos nossas crenças. Na segunda seção, irei discutir as possíveis relações entre responsabilidade epistêmica e responsabilidade moral, argumentando contra a tese defendida por Clifford de que há uma correlação entre as responsabilidades epistêmicas e morais. Assumirei como correta a tese de que há apenas uma sobreposição eventual entre estes dois tipos de responsabilidades. Na terceira seção, apresentarei a teoria de vícios epistêmicos de Cassam e sua forma de compreender responsabilidade epistêmica, para por fim, na seção quatro, aplicar esta discussão ao contexto das fake news.

\section{1. Ética da crença em W. K. Clifford}

Para começar nossa reflexão sobre ética da crença, em especial para discutir o tema das fake news, me parece apropriado fazer uma pequena viagem ao texto clássico de W. K. Clifford intitulado "Ética da crença". Isso porque Clifford, neste texto constrói argumentos bastante convincentes que nos levam a conclusões que, apesar de um pouco radicais, parece ser o que buscamos como meta quando hoje pensamos em como as pessoas acreditam, talvez ingenuamente, em qualquer coisa que aparece em suas redes sociais. Clifford inicia seu ensaio contando a história de um armador que está a ponto de enviar ao mar um navio cheio de pessoas. O navio era um navio 
velho, que precisava de reparações por conta de defeitos de construção, mas que também por muitas viagens suportou tranquilamente sem nenhum acidente grave. Ele tinha dúvidas sobre se o navio tinha condições de navegar, mas reparar todo o navio sairia muito caro. Então, ele decidiu confiar na crença de que o navio já havia suportado muitas viagens e que nada iria ocorrer nesta viagem. O navio naufragou em pleno mar sem deixar rastro e matando centenas de pessoas, e o armador ainda recebeu o dinheiro do seguro.

Nesta história temos outro exemplo de vidas que foram ceifadas por conta de uma crença falsa, neste caso, a crença de que não era necessário um reparo no navio e que ele suportaria bem a viagem. Clifford sobre esse caso nos diz que o armador "não tinha o direito de acreditar com base nos indícios de que dispunha" (2010, p. 98). Porém, Clifford vai um pouco além. Ele nos pede que imaginemos que nada aconteça com o navio. A viagem é bem-sucedida e nenhuma pessoa morre. Como avaliar o direito do armador a ter a crença que tinha? A resposta de Clifford é a de que isso "tem a ver com a origem da crença do armador, e não com o seu conteúdo; não é a crença que conta, mas o modo como a adoptou; não se trata de a crença ser afinal verdadeira ou falsa, mas de o armador ter ou não o direito a acreditar com base nos indícios de que dispunha" (2010, p. 99). A avaliação de Clifford não recai sobre se a crença a final é verdadeira ou falsa, mas sim em como nós obtemos ou formamos essa crença. Se não obtemos ou formamos nossa crença de modo adequado, não temos o direito de ter essas crenças. Assim, nada melhor que o famoso slogan de Clifford (2010, p. 108) para resumir esta ideia:

Ética da Crença: É sempre incorreto, em todo o lado, para qualquer pessoa, acreditar seja no que for com base em indícios insuficientes.

Importante ressaltar que a avaliação de Clifford é epistêmica e moral. Ou seja, é sempre epistemicamente e moralmente incorreto, não importa o contexto, não importa a pessoa, crer no que quer que seja com base e indícios insuficientes. Esse slogan parece refletir bem a preocupação de Clifford quando voltamos aos exemplos da Escola Base ou da Fabiane, que perdeu a vida por conta de pessoas que acreditavam sem indícios suficientes que ela 
era uma sequestradora de crianças. Não é difícil, de fato, encontrar casos em que pessoas perderam a vida por conta de crenças que foram obtidas ou formadas com base em indícios insuficientes.

Outro aspecto que vale a pena destacar é que este slogan de Clifford tem por detrás alguns pressupostos. Primeiro, o de que toda ação é realizada com base na influência de uma ou mais crenças. Por isso, mesmo que a crença de que o navio pode suportar mais uma viagem seja verdadeira, a ação que dela decorre, a de permitir o navio realizar mais uma viagem sem passar antes por reparos e revisões é uma ação incorreta, imoral, porque a crença se sustenta em indícios insuficientes. O segundo pressuposto é a ideia de que de algum modo, temos controle sobre nossas crenças. Isso porque dizer que é incorreto crer com base em indícios insuficientes parece implicar que podemos fazer o correto se desejarmos, ou seja, podemos de algum modo decidir a crer ou a não crer em algo. Este é o pressuposto do voluntarismo doxástico. O terceiro pressuposto é o de que temos um sistema único de crenças em nosso aparato cognitivo. E por isso, por mais inocente que uma crença possa aparentar ser, ela faz parte de um sistema de crenças. Assim, se esta crença inocente foi adquirida de modo irresponsável com base em indícios insuficientes, ela estará sendo incluída em um sistema de crenças e pode, assim, contaminar este sistema nos preparando para receber mais crenças semelhantes, irresponsáveis, confirmando algumas crenças pré-existentes e enfraquecendo outras, de modo que gradualmente "estabelece um fio condutor implícito nos nossos pensamento mais íntimos, que pode um dia manifestar-se em ações inequívocas e deixar a sua marca no nossos caráter para sempre" (CLIFFORD, 2010, p. 103).

O quarto pressuposto é uma generalização do segundo. Assim como nossa crença faz parte de um sistema de crenças e uma crença indevida, por mais inocente que seja, pode contaminar como uma doença todo o sistema de crenças e causar ações irresponsáveis no futuro, nós, como pessoas, somos parte de um sistema social. Por isso que para Clifford, "em circunstância alguma a crença de um homem é um assunto privado, que apenas diga respeito ao próprio" (CLIFFORD, 2010, p. 103). O meu hábito de crer com base em indícios insuficientes pode estimular e contaminar a outras pessoas a seguirem meu exemplo, formando suas crenças de modo igualmente irres- 
ponsável e sem interesse ou preocupação com indícios que comprovem ou rejeitem nossas crenças), contaminando assim toda a sociedade e tendo como consequência uma sociedade que atua de modo totalmente irresponsável com base em crenças infundadas. É nossa obrigação moral cuidar de nossas crenças para evitar que uma crença infundada e um hábito infundado de formar crença se espalhe em nossa sociedade como um vírus em uma pandemia (CLIFFORD, 2010, p. 106), assim como é nosso dever, em tempos de pandemia de vírus respiratórios como o Covid-19. Usar máscaras e manter a distância das pessoas quando vamos sair para evitar que o vírus se propague e gere um alto número de mortes.

Poderíamos talvez dizer que Clifford está aqui falando diretamente sobre aquela pessoa, que chamarei aqui de Mark, que recebe via WhatsApp certas informações, e sem questionar, apenas crê na informação e compartilha tal crença em seus grupos de WhatsApp. Nestes grupos, as pessoas são bombardeadas por estas crenças infundadas e irresponsáveis, e acabam de algum confiando em Mark. Além disso, as pessoas acabam acreditando, igualmente de modo irresponsável, sem ter o direito a crer nestas crenças, e passam a repetir o comportamento irresponsável e imoral de Mark. Por isso que o ato irresponsável de se crer com base em evidências insuficientes pode se espalhar pela sociedade assim como um vírus se espalha mundialmente e gera uma pandemia. Entretanto, parece que aqui teríamos um problema para a teoria de Clifford: é impossível para uma pessoa buscar evidências para todas as crenças possíveis. Não devo ser obrigado a investigar sobre química e biologia para saber se um determinado medicamento funciona ou não para aliviar minhas dores de cabeça. Devemos ser, portanto, de algum modo, autorizados a acreditar nos que dizem aquelas pessoas que consideramos autoridades.

E Clifford de fato concede isso. Porém, sem nunca deixar de lado a sua máxima de que devemos sempre, em todos os casos, buscar evitar crer com bases em indícios insuficientes. Ou seja, antes de simplesmente acreditar no que nos diz uma outra pessoa, devemos sempre buscar investigar em que circunstâncias é legitimo acreditar no que os outros nos dizem. É preciso verificar se a pessoa tem por exemplo, o costume de mentir, se conhece ou desconhece um tema, se é especialista ou não no assunto que fala, se ela 
tem interesse e preocupação pela verdade, e se ela também busca sempre crer com base em bons indícios (CLIFFORD, 2010, p. 113). Se vou a um médico cardiologista e ele me explica sobre doenças do coração, estou autorizado a acreditar nele porque posso supor que por ser um médico cardiologista, estudou muitos anos sobre essas doenças. Que por continuar na prática médica, tem tido bons resultados com seus pacientes, o que sugere o interesse pela verdade, etc. Tudo isso me autoriza a crer neste médico, quando ele fala sobre cardiologia. Mas isso não autoriza o médico a falar sobre todos os assuntos. Se este mesmo médico posta em suas redes sociais informações sobre engenharia, física quântica ou política, eu posso até imaginar que ele talvez esteja usando os mesmos métodos de pesquisa e investigação que usou para aprender assuntos da medicina, e que ele possui certos interesses pela verdade, mas, será que ele tem de fato indícios suficientes para crer e falar sobre todos estes outros temas? A resposta de Clifford a esta preocupação parece clara: “A bondade e a grandeza de um homem não nos dão justificação para aceitar uma crença com base na sua autoridade, a menos que haja uma base razoável para supor que conhece a verdade daquilo que afirma" (CLIFFORD, 2010, p. 120). Desse modo, somente estamos autorizados a crer no que outra pessoa nos afirma quando "há uma base razoável para supor que ela conhece o assunto de que fala, e que fala a verdade tanto quanto a sabe" (CLIFFORD, 2010, p. 120).

Se voltarmos ao caso do personagem Mark, do WhatsApp, compreendemos que talvez para muita gente dos grupos em que ele frequenta, ele seja uma autoridade. Por isso é compreensível que as pessoas aceitem ingenuamente tudo o que ele compartilha e passem a crer também no mesmo. Mas de acordo com Clifford, é sempre fundamental buscar indícios sobre se Mark de fato sabe sobre o que fala e se tem a preocupação e o interesse pela verdade. As pessoas que não se preocupam em investigar estes aspectos sobre o Mark e acreditam em tudo o que ele compartilha estão inevitavelmente, segundo Clifford, sendo irresponsáveis, epistemicamente e moralmente. Estas pessoas não têm o direito de acreditar nestas crenças.

O que podemos perceber nesta breve contextualização do texto do Clifford é que são ideias com fortes apelos e conexões com problemas atuais que de nossa vida cotidiana. Porém, apesar do apelo, a teoria de Clifford en- 
frenta uma série de dificuldades ${ }^{5}$. Não pretendo aqui fazer uma discussão crítica de cada um dos problemas, mas sim, concentrar-me na relação entre a responsabilidade epistêmica e moral. Na avaliação de Clifford, onde há responsabilidade epistêmica, por conta do primeiro pressuposto, há responsabilidade moral. É sobre este ponto que pretendo discutir neste momento.

\section{A relação entre a responsabilidade epistêmica e moral}

Susan Haack, em seu texto "The Ethics of Belief" Reconsidered (2001) faz uma análise bastante cuidadosa da relação entre as avaliações epistêmicas e morais. Será que toda avaliação epistêmica, ou seja, será que em todos os casos onde há responsabilidade epistêmica há também responsabilidade moral, como pensava Clifford? Antes de Haack (2001, p. 21) responder esta pergunta, ela descreve cinco possíveis relações entre as avaliações epistêmicas e morais:

1 A avaliação epistêmica é uma subespécie da avaliação ética - a tese do caso especial;

2 As avaliações epistêmicas positivas/negativas são distintas, mas invariavelmente associada com as avaliações éticas positivas/negativas - a tese da correlação;

3 Existe uma sobreposição parcial, onde avaliações epistêmicas positivas/negativas são associadas com avaliações éticas positivas/negativas - a tese da sobreposição;

4 As avaliações éticas são inaplicáveis onde as avaliações epistêmicas são relevantes - a tese da independência;

5 As avaliações epistêmicas são distintas, porém análogas, às avaliações éticas - a tese da analogia;

Clifford não descreve claramente o que ele pensa sobre a relação entre as avaliações éticas e avaliações epistêmicas. Porém, podemos concluir facilmente pelas discussões dos casos anteriores e do famoso slogan de Clifford que ele estaria defendendo a tese da correlação. As avaliações epistêmi-

\footnotetext{
${ }^{5}$ Não é intenção minha aqui apontar os problemas que poderiam por exemplo tornar a teoria de Clifford inviável. Mas é importante ressaltar que o texto de Clifford foi fundamental para toda a discussão sobre ética da crença da epistemologia contemporânea. Para uma compreensão mais atual sobre este debate, ver STEUP (2001) e MATTHESON E VITZ (2014).
} 
cas são distintas das avaliações morais, porém, são invariavelmente associadas: sempre que a avaliação epistêmica for negativa, a avaliação ética também será. Se é sempre errado, epistemicamente, crer e bases de indícios insuficientes, as ações que se seguem dessas crenças são também moralmente condenáveis. Haack, em seu texto, procura argumentar que a tese da correlação é falsa, e defende como correta a tese da sobreposição.

Para negar a tese da correlação, Haack busca alguns contraexemplos. Casos, por exemplo, em que há uma crença injustificada, mas que que são crenças inofensivas ou mesmo benéficas. Para isso, ela descreve possíveis explicações para que alguém acredite de modo injustificado (HAACK, 2001, p. 24): quando há uma incontinência negligente, ou seja, a pessoa foi descuidada ou superficial em sua investigação, acreditando mesmo assim; quando há autoengano, ou seja, a pessoa, por interesses próprios, pesa as evidências de modo enviesado; e quando há inadequação cognitiva, quando a pessoa faz o máximo possível, mas ainda assim isso não é o suficiente para que ela acredite de modo justificado. A inadequação cognitiva pode ser do tipo pessoal, ou seja, a pessoa por alguma limitação ou erro de boa-fé pesa inadequadamente as evidências, ou cultural, quando a pessoa não tem condições de perceber que as crenças de fundo que ela possui e considera relevantes são crenças incorretas, por conta da influência sociocultural (HAACK, 2001, p. 21).

Vamos ver alguns exemplos. Se uma pessoa digamos faz o seu melhor, mas ainda assim falha em crer com base em indícios suficientes, devemos concluir que ela é moralmente culpada por alguma ação que se segue disso? Mesmo se a crença dela for uma crença ainda assim a princípio inofensiva (como crer que uma fruta está madura quando não está)? Parece que as exigências da tese da correlação são muito fortes para dizer que ainda nesses casos, a pessoa é moralmente culpada por crer dessa forma. Paradoxalmente, Clifford estava mais interessados nos hábitos negativos de crer com base em indícios insuficientes do que com erros pontuais. Mas ele usa, em seu slogan, o termo "sempre", o que nos leva a crer que ainda assim, casos pontuais de erros ou limitações cognitivas devam ser julgadas negativamente, tanto epistemicamente quanto moralmente. Se Clifford está correto de que é sempre errado, devemos concluir que é uma obrigação moral estar 
sempre consciente de todas nossas limitações cognitivas, nossos vieses cognitivos, as influências culturais e sociais em nossa forma de pensar, etc. Essa demanda é altíssima, para não dizer, talvez impossível.

Pensemos em casos de limitações cognitivas por origem cultural. Uma pessoa que cresce em uma determinada cultura onde lhe é ensinado que se comer manga e tomar leite logo depois, ela pode morrer. E ela não tem condições de crer de forma diferente disso, por limitações cognitivas culturais. ${ }^{6}$ Será que é correto dizer que esta pessoa é epistemicamente responsável, culpada por ter esta crença? E será que ela deve ser moralmente responsabilizada por algum ato que se siga desta crença? Podemos imaginar que esta pessoa está conversando com um amigo que está comendo manga, e este amigo se engasga, sendo que a única maneira de salvar seria dando um copo de leite. Ela não entrega o copo de leite para a pessoa, pois acredita que fazer isso pode provocar a morte do seu amigo, e por isso, seu amigo acaba morrendo engasgado. Esta pessoa é moralmente responsável pela morte de seu amigo? Haack sugere que não.

O caso acima é um caso de ignorância desculpável. Por conta das limitações cognitivas culturais, a pessoa não tem como obter a crença verdadeira, mesmo que deseje. A sua ignorância, neste caso, serve tanto como desculpa moral como desculpa epistêmica ${ }^{7}$. Para Haack. A forma moralmente culpável de ignorância é o que ela chama de "ignorância voluntária", ou seja, a ignorância que é resultado de algum tipo de incontingência negligente ou autoengano (HAACK, 2001, p. 25). Se o argumento de Haack está correto, então a tese da correlação é falsa, ou seja, não é o caso de que sempre, toda responsabilidade epistêmica implica responsabilidade moral. E a tese que Haack, portanto, considera a correta é a tese da sobreposição: há casos de responsabilidade epistêmica que implica em responsabilidade moral (como casos de ignorância voluntária), porém, haverá casos de responsabilidade epistêmica que não implica em responsabilidade moral e vice-versa.

\footnotetext{
${ }^{6}$ Conta-se a história de que na época da escravidão, os senhores de engenho não queriam que seus escravos bebessem o leite, para assim lucrar mais com a venda do mesmo. Sabendo que os escravos comiam bastante manga, os senhores inventaram a história de que mis turar manga com leite era fatal. Independente da veracidade desta história, podemos supor a mesma, tornando este caso um caso de limitação cognitiva cultural.

${ }^{7}$ Para uma discussão mais aprofundada sobre a relação entre tipos de ignorância e moralidade, ver PEELS (2017).
} 
Casos de ignorância desculpável são casos onde não há responsabilidade epistêmica nem moral. Quais são os casos onde há responsabilidade epistêmica, mas não há responsabilidade moral? Estes são os casos em que as crenças são inofensivas. Se creio, com base em indícios insuficientes, que uma determinada fruta está madura, quando não está, posso ser considerado epistemicamente responsável por esta crença. Mas isso implica que sou moralmente responsável por ela, mesmo que ela não cause nenhum dano real a mim, a outras pessoas, à sociedade?

Vimos anteriormente que a resposta de Clifford é que sim, e por duas razões. A primeira é porque essa crença faz parte de um sistema de crenças e pode, potencialmente, causar danos no futuro. Não há crença totalmente inofensiva em nosso sistema de crenças, segundo Clifford. E a segunda razão é porque crer com base em indícios insuficientes pode gerar vícios de sempre investigar de modo irresponsável, preguiçoso, com a mente fechada, e isso tem o potencial não só moral de causar danos, mas de contaminar a sociedade com estes péssimos hábitos, com esses vícios. Haack afirma que a resposta de Clifford depende de duas premissas falsas (HAACK, 2001, p. 27): a primeira de que o mero potencial remoto para causar dano é suficiente para uma avaliação moral negativa. Ora, se isso fosse o caso, como descreve Haack, não apenas dirigir embriagado faria alguém moralmente culpável, mas também possuir um carro, pois é uma mera possibilidade remota de que ao possuir o carro posso matar alguém ao dirigir. A segunda premissa falsa, segundo Haack, é a de que o sujeito é sempre responsável ao crer de modo injustificado, porém, como discutimos anteriormente, casos de limitações cognitivas servem como desculpa para a responsabilidade epistêmica, segundo Haack. Além destas duas premissas falsas, eu acrescentaria uma terceira, que é a ideia de que há uma espécie de holismo e nosso sistema de crenças. ${ }^{8}$ Sendo correto este raciocínio, temos então exemplos de responsabilidade epistêmica que não implica em responsabilidade moral, fortalecendo assim ainda mais a tese da sobreposição, defendida por Haack.

\footnotetext{
${ }^{8}$ Segundo teorias da psicologia evolutiva, nossas crenças, valores e desejos são armazenadas em compartimentos distintos no nosso cérebro, e não em um compartimento único interconectado. Para saber mais, ver KURZBAN (2010).
} 
Mesmo sendo insatisfatória a resposta de Clifford para os casos discutidos acima, a preocupação dele de que mal hábitos de investigação possam encorajar outras pessoas a também agir de modo irresponsável é uma preocupação válida. Nas palavras de Clifford, o "perigo para a sociedade não é meramente o de acreditar em coisas erradas, embora isso seja suficientemente mal; mas o de se tornar crédula e perder o hábito de testar as coisas e de as investigar; pois então reincidirá forçosamente na selvajaria" (CLIFFORD, 2010, p. 107). Talvez não seja o caso, com discutimos acima, que todas as formas de se crer com base em indícios insuficientes possam justificar a preocupação de Clifford a respeito do hábito da credulidade. Como aponta Haack (2001, p. 30), as avaliações epistêmicas compartem com as avaliações éticas certo vocabulário, como "negligência", "honestidade", dentre outros. Dentre outras coisas, isso parece sugerir que há uma importância moral ao que chamamos de integridade intelectual, motivando a preocupação a respeito do hábito da credulidade. Sendo assim, a melhor forma de verificar se esta preocupação de fato se segue, não para todos os casos, mas talvez para alguns, é investigar mais profundamente quais são estes hábitos epistêmicos negativos, ou mais precisamente, quais são e o que são os vícios epistêmicos.

\section{Vícios epistêmicos e responsabilidade}

O que são os vícios epistêmicos?? $\mathrm{E}$ como a compreensão de vícios epistêmicos pode nos ajudar a analisar melhor as nossas responsabilidades intelectuais? A epistemologia durante muito tempo focou sua atenção para a discussão sobre virtudes intelectuais, ${ }^{10}$ porém, muita pouca atenção para a discussão sobre vícios. Um dos filósofos mais ativos na discussão sobre vícios intelectuais é Quassim Cassam, em especial com seu livro Vices of the Mind (2019). Nesta seção, iremos nos aprofundar mais nas duas

\footnotetext{
${ }^{9}$ Irei utilizar a terminologia "vícios intelectuais" como sinônimo de "vícios epistêmicos" neste texto.

${ }^{10}$ Uma vasta literatura foi produzida nos últimos quarenta anos sobre virtudes intelectuais, sendo que dois tipos de teorias se destacaram na literatura. A versão confiabilista de virtudes intelectuais (SOSA, 2015; GRECO, 2010), que é uma espécie de consequencialismo por estar interessado na confiabilidade dos processos e performances produtoras de conhecimento; e a versão responsabilista (ZAGZEBSKI, 1996), que realiza uma maior aproximação com a ética das virtudes, dando maior atenção às motivações do crente.
} 
perguntas do início deste parágrafo, relacionando-as com a discussão feita nas seções anteriores.

Como vimos nas seções anteriores, a preocupação principal não era com o fato de ser a crença verdadeira ou falsa, mas sim, com o ato de se acreditar com base em indícios insuficientes. Susan Haack qualificou mais este ponto, destacando que algumas vezes fazemos o máximo possível e ainda assim acreditamos com base em indícios insuficientes, e isso não nos torna culpados por tais crenças. A teoria de vícios intelectuais de Cassam dá um passo à frente, fornecendo uma regra mais ampla que nos permite analisar diversos casos de modo individual. Primeiramente, vamos compreender o que são os vícios epistêmicos:

Vício Epistêmico: Um vício epistêmico é um traço de caráter culpável ou repreensível, atitude ou modo de pensar que obstrui sistematicamente a conquista, manutenção ou compartilhamento de conhecimento. (CASSAM, 2019, p. 23)

Esta teoria é conhecida como Obstrucionismo. O obstrucionismo é uma espécie de consequencialismo, pois está mais interessado na consequência de determinados atos do que com motivações ou intenções. Antes de avançarmos, é importante deixar claro três condições fundamentais que precisam ser obtidos para que algo seja considerado vício epistêmico. A primeira condição diz que vícios intelectuais envolvem não somente traços de caráter do sujeito, mas também atitudes intelectuais ou modos de pensar. A segunda condição diz que tais traços de caráter, atitudes e modos de pensar somente são considerados vícios se estão sistematicamente obstruindo a obtenção, manutenção e compartilhamento de conhecimento ${ }^{11}$. E a terceira diz que tais traços de caráter, atitudes e modos de pensar somente são considerados vícios se são de algum modo repreensíveis ou merecedores de culpa. Se as três condições não são obtidas, então não temos um vício intelectual.

Qual a natureza dos vícios epistêmicos? Segundo a primeira condição da definição acima, os vícios epistêmicos podem ser tanto os traços de

\footnotetext{
${ }^{11}$ Cassam defende a seguinte que conhecimento exige crença verdadeira e além disso que exista confiança razoável na verdade de $P$ (CASSAM, 2019, p.10). Neste texto não irei discutir a compatibilidade da teoria dos vícios epistêmicos com outras possíveis definições de conhecimento. Aceitarei, a princípio, que esta teoria é compatível com as principais teorias de conhecimento disponíveis.
} 
caráter de uma pessoa, como também atitudes intelectuais ou modos de pensar. Traços de caráter são "disposições estáveis para agir, pensar e sentir de modo particular" (CASSAM, 2019, p. 12). Uma pessoa que é arrogante, por exemplo, é uma pessoa que possui disposições para agir de modo arrogante nos mais diversos contextos, ou seja, é uma pessoa que em geral age com o sentido de superioridade em relação aos outros, atua de modo agressivo, etc. Dizemos que neste caso a arrogância é parte do caráter da pessoa devido a estabilidade da disposição nos mais variados contextos possíveis. Entretanto, uma pessoa pode não ser arrogante, ou seja, não possuir o traço de caráter de arrogância, mas ter atitudes arrogantes. Atitudes são "orientações ou posturas em relação a algo". Então, uma pessoa que não é arrogante pode ter atitudes de arrogância em direção a outra pessoa específica. Em uma situação específica, um sujeito $\mathrm{S}$ pode comportar-se sentindo-se superior a outra pessoa (quando isto não é o caso), e por conta disso, pode passar a considerar irrelevante tudo o que outra pessoa diz, pois em sua cabeça, sua superioridade implica em saber mais do que a outra pessoa, naquele momento.

Outro exemplo de atitude é o preconceito. Quando uma pessoa branca, por exemplo, age com um sentido de superioridade em relação a uma pessoa negra, ignorando tudo o que a pessoa negra diz, pois em sua cabeça, "uma pessoa negra não tem capaz de saber essas coisas", estamos diante da atitude de preconceito intelectual. Alguém pode ter como objeção que o preconceito é um traço de caráter. No caso específico citado, pode-se dizer que é o caso de uma pessoa racista. O racismo, como disposição estável para agir em diversos contextos, é o traço de caráter, que envolve agir com preconceito em relação a outras pessoas. Mas nem todos os casos de atitudes preconceituosas envolvem necessariamente a existência de racismo ou machismo por exemplo. Assim como_uma pessoa que é arrogante exige de modo estável atitudes arrogantes, nem toda atitude arrogante implica que a pessoa e questão possui os traços de caráter de arrogância. $O$ ponto aqui não é fazer uma análise específica de cada traço de caráter e cada tipo de atitude intelectual, mas apenas o de destacar que existe uma relação entre atitudes e traços de caráter, mas também existe uma diferença entre estes dois tipos de vícios epistêmicos. 
Além das atitudes e traços de caráter, Cassam também descreve modos de pensar como vícios epistêmicos. Por exemplo, o pensamento ilusório $^{12}$ não é um traço de caráter de uma pessoa e nem mesmo uma atitude, pois não é uma orientação ou postura em relação a algo, mas apenas uma maneira específica de se pensar. Uma pessoa pode ter caráter epistêmico bom, atitudes corretas perante outras pessoas, mas em alguns momentos, ao obter certas informações, pensar sobre elas, pode incluir o pensamento ilusório eventualmente em seu raciocínio. Sendo o pensamento ilusório um vício epistêmico, a pessoa estaria pensando de modo irresponsável.

A segunda condição da definição de vícios intelectuais nos diz que tais traços de caráter, atitudes e modos de pensar somente são considerados vícios se estão sistematicamente obstruindo a obtenção, manutenção e compartilhamento de conhecimento. Como isso ocorre? Vejamos com os exemplos já descritos acima. O pensamento ilusório é um modo de pensar onde “os desejos do pensante possui mais influência que considerações lógicas e evidenciais" (CASSAM, 2019, p. 13). Uma pessoa pode pensar que por ser religiosa, é protegida de Deus e não se contaminará por nenhum vírus, por mais contagioso que o vírus seja. Esse modo de pensar impede que esta pessoa obtenha conhecimento sobre como funciona a propagação de doenças, quais cuidados devem ser tomados para evitar que pessoas se contagiem e morram de determinadas doenças, etc. A pessoa simplesmente coloca seu pensamento ilusório como superior a qualquer tipo de evidência, e a grande maioria das vezes que o pensamento ilusório está presente, não há obtenção de conhecimento (mesmo se, por sorte, a crença no final das contas seja verdadeira). Assim, o modo de pensar ilusório obstrui sistematicamente a obtenção de conhecimento e também o compartilhamento de conhecimento, pois podemos supor que a pessoa do exemplo acima é um líder religioso e possivelmente compartilhará seu modo de pensar ilusório com sua comunidade religiosa, impedindo que os mesmos obtenham conhecimento sobre a atuação do vírus.

Atitudes, como o preconceito, funcionam de modo similar. Por exemplo, um caso de arrogância onde o sujeito, por se crer superior, não

\footnotetext{
${ }^{12}$ Com "pensamento ilusório" estou me referindo ao que em inglês é conhecido como "whishfull thinking".
} 
atribui crédito epistêmico a seu interlocutor, ou atribui menos relevância ao que ele diz não estará avaliando corretamente as crenças que possui e as evidências disponíveis que outras pessoas poderiam compartilhar com ela. Este tipo de atitude claramente a impedira de considerar adequadamente evidências e informações e portanto, a impedirá de obter conhecimento. Na grande maioria dos casos em que este tipo de atitude está presente, a obtenção, manutenção ou mesmo o compartilhamento de conhecimento não ocorre. Claro, de novo, há casos em que é possível que uma pessoa seja arrogante e de fato obtenha ou mantenha conhecimento, porque mesmo que ela desmereça o que a outra pessoa diz, por mero acaso, o que a outra pessoa diz não é relevante para a manutenção da crença que ela possui. Mas de novo, a definição de vícios intelectuais apenas nos diz que vícios sistematicamente obstrui a obtenção, manutenção e compartilhamento de conhecimento, e não que invariavelmente obstrui. O mesmo raciocínio funciona para traços de caráter, que sistematicamente obstruí a obtenção, manutenção e compartilhamento de conhecimento. ${ }^{13}$

Se no início deste texto vimos que Clifford dizia que não devíamos crer com base em evidências insuficientes, com Cassam temos uma compreensão diferente do que parece ser problemático. O problema não é eventualmente crer com base em evidências insuficientes, mas sim, crer de forma viciosa, pois esta forma de se crer se caracteriza justamente pelo fato de sistematicamente obstruir o acesso ao conhecimento. Como Haack bem demonstrou, se uma pessoa faz o seu melhor, busca crer de modo não vicioso, analisa adequadamente as evidências, mas por alguma razão acaba crendo com base em evidências insuficientes, não teremos, em princípio, um problema. Mas o que dizer de casos como os de limitações cognitivas culturais, como os descritos por Haack, onde a pessoa não teria como crer diferente? Não seria um modo de pensar que sistematicamente obstrui a obtenção de conhecimento? Cassam definiria tais casos como vícios epistêmicos ao contrário do que sugere Haack, que são casos desculpáveis? Para responder esta pergunta, é importante voltar a atenção para a terceira condição da definição

\footnotetext{
13 Por uma questão de limitação de espaço, não entrarei em detalhes sobre as diferenças mais específicas entre modos de pensar, atitudes e traços de caráter, e em como especificamente cada um obstrui o conhecimento. O foco deste artigo é na discussão sobre a responsabilidade.
} 
de vícios epistêmicos. Como vimos, não basta apenas que sejam traços de caráter, atitudes e modos de pensar que sistematicamente obstrua a obtenção, manutenção e compartilhamento de conhecimento. Para ser considerado um vício epistêmico, é necessário que tais traços de caráter, atitudes e modos de pensar sejam de algum modo repreensíveis ou digno de culpa.

Aqui já há uma distinção importante que merece destaque. Os vícios epistêmicos devem envolver ou culpa ou ser de algum modo repreensível. Isso significa que é possível que certos vícios intelectuais sejam repreensíveis, merecedores de crítica, porém, não envolver culpa. Obviamente, os vícios que são dignos de culpa são repreensíveis. De acordo com Cassam, "a culpa de um vício é atribuída à pessoa cujo vício é mais do que ao próprio vício: um vício digno de culpa é aquele pelo qual a pessoa cujo vício é merece culpa" (2019, p. 123). Como estamos falando de vícios epistêmicos, então o que está em discussão aqui é culpa epistêmica, por conta das falhas intelectuais em jogo. Ou seja, não é porque há culpa moral que há também culpa epistêmica, e não é porque há culpa epistêmica que há também culpa moral. Cassam, assim como Haack, defende uma espécie de tese da sobreposição. As falhas em questão "também podem ou não se qualificar como falhas morais que merecem culpa moral" (CASSAM, 2019, p. 123). Mas afinal, o que faz com que uma pessoa mereça culpa por sua falha? Para que uma pessoa mereça culpa, duas condições devem ser satisfeitas: a primeira, diz que "para uma pessoa $\mathrm{S}$ ser culpada [pelo vício] V deve ser o caso que V seja nocivo [...] para S ou para outras [pessoas]" (CASSAM, 2019, p. 18). Além disso, também deve ser satisfeita a segunda condição, que diz que "S é culpado por $\mathrm{V}$ somente se $\mathrm{V}$ é um traço de caráter, atitude ou modo de pensar pelo qual S é responsável" (CASSAM, 2019, p. 18). E por responsabilidade, Cassam implica algum tipo de controle que a pessoa possui pelo traço de caráter, atitude ou modo de pensar.

A discussão sobre possibilidade de controle dos nossos estados mentais não é uma discussão nova. Mas ciente disso, Cassam busca definir o controle de uma maneira que não seja forte o suficiente que torne a possibilidade de controle impossível. Assim, ele define dois tipos de responsabilidades: Responsabilidade de aquisição, onde a pessoa é responsável pelo vício $\mathrm{V}$ porque adquiriu voluntariamente ou voluntariamente desenvolveu $\mathrm{V}$, 
através de hábitos, treinamento ou mesmo imitação (CASSAM, 2019, p. 18); e responsabilidade de revisão, onde $\mathrm{S}$ possui a habilidade de modificar voluntariamente seus traços de caráter, atitude e modo de pensar, mas não o faz. Desse modo, se para o vício V é de algum modo nocivo (ao portador do vício ou a outros) e o sujeito $\mathrm{S}$ possui algum tipo de controle, seja de aquisição seja o de revisão, então S é culpado, epistemicamente pelo menos, pelo vício epistêmico.

Na segunda seção vimos um exemplo de limitação cognitiva cultural onde, segundo Haack, esta limitação poderia servir como desculpa epistêmica, já em casos assim, parece não haver controle por parte do sujeito sobre a atitude, caráter ou modo de pensar. Um exemplo similar, dado por Heather Battaly (2016, p. 100) é analisado por Cassam. Imaginem um jovem cujo dogmatismo é o resultado de ter passado a vida toda sendo doutrinado pelo Talibã. O jovem tem culpa por seu dogmatismo? Claramente o dogmatismo é epistemicamente nocivo (e pode ser também moralmente nocivo, dado que por conta deste dogmatismo, o jovem pode por exemplo, acreditar que mulheres são "seres inferiores" que não merecem direitos e trata-las de modo violento, agredindo-as. Caso o jovem atuasse assim, obviamente seria moralmente culpado por sua violência contra a mulher. Mas no que diz respeito a culpa epistêmica, Cassam afirma que "uma das formas de justificar a discussão sobre vícios em casos assim é argumentar que mesmo que o recruta talibã não possua a responsabilidade de revisão pelo seu dogmatismo, não faz parte da natureza do dogmatismo em geral não ser revisável” (2019, p. 21). Por isso, é fundamental analisar cada caso. Há casos em que o dogmatismo é revisável, e, portanto, o portador do dogmatismo é culpado epistemicamente por seu dogmatismo. Mas e se neste caso específico este dogmatismo não for revisável? Mesmo que não seja revisável, para Cassam este dogmatismo ainda é um vício epistêmico, mas não porque S seja digno de culpa pelo dogmatismo específico, onde $\mathrm{S}$ não possui nem responsabilidade por aquisição nem por revisão. E sim, porque este dogmatismo, ainda assim, é repreensível. Este é um exemplo em que $\mathrm{S}$ possui um vício epistêmico, mas não é culpado pelo mesmo.

Com base nestas distinções, Cassam sugere a seguinte forma de classificar os defeitos cognitivos e vícios epistêmicos: 
[...] para começar, existem defeitos cognitivos para os quais nem a culpa nem a crítica são apropriadas. Esses são "meros" defeitos cognitivos, em vez de vícios epistêmicos. Por exemplo, embora ser cego de nascença seja certamente um obstáculo a alguns tipos de conhecimento [...] seria extremamente inapropriado criticar a cegueira de uma pessoa, muito menos considerá-la culpável por ser cega. Em segundo lugar, existem falhas intelectuais que certamente estão sujeitas a críticas e, neste sentido repreensível, mas por um motivo ou outro não culpável. Talvez, como o dogmatismo do recruta talibã, eles falhem no teste de responsabilidade por culpa. Por fim, existem falhas intelectuais que não são apenas repreensíveis (abertas a críticas), mas também culpáveis, no sentido epistêmico de 'culpáveis'. Como a responsabilidade da revisão por um vício epistêmico pode variar de pessoa para pessoa, um e o mesmo vício epistêmico pode ser culpado em alguns casos, sem ser culpado em todos os casos. (CASSAM, 2019, p. 21)

E como diferenciar os casos que são meros defeitos de casos de vícios que merecem crítica? Os meros defeitos cognitivos, como a cegueira, ou uma pessoa que possui algum tipo de problema neurológico que causa constantemente esquecimento nela, são defeitos que não refletem negativamente sobre quem a pessoa é. Criticar uma pessoa por ela ser cega ou por ela possuir uma doença que causa esquecimento parece ser mais um ato de agressão à pessoa do que uma crítica justa a quem ela parece ser. Entretanto, casos como o dogmatismo do jovem talibã é um caso de um defeito epistêmico que reflete negativamente sobre quem ele é. Nas palavras de Cassam, “o que conta não é se eles [os defeitos epistêmicos] definem o tipo de pessoa que ele é mas sim se define o tipo de pensador ou conhecedor ele é" (2019, p. 134). O dogmatismo do talibã reflete que tipo de pensador o jovem é, mesmo que ele não seja afinal culpado por ser este tipo de pensador. Assim, em certo sentido o diagnóstico de Haack está correto ao dizer que há casos em que há uma desculpa que isenta a pessoa da culpa epistêmica. Mas por outro lado, essa isenção de culpa não é necessariamente uma isenção de crítica e muito menos da responsabilidade moral que pode se seguir das crenças formadas através do vício epistêmico. E cada caso deve ser avaliado de modo isolado, pois o dogmatismo de uma pessoa pode ser um dogmatismo merecedor de crítica, mas não de culpa, enquanto o de outra pessoa pode ser um dogmatismo digno de crítica e culpa epistêmica.

Enquanto que na primeira seção deste artigo vimos que é sempre (moralmente e epistemicamente) incorreto acreditar seja no que for com 
base em indícios insuficientes, nesta seção podemos concluir algo que, acredito, nos permite realizar um diagnóstico mais preciso e justo sobre as normas epistêmicas, a saber, que é sempre epistemicamente incorreto formar, manter ou compartilhar crenças com bases em vícios intelectuais. Epistemicamente incorreto não porque o sujeito que crê assim é epistemicamente culpado pelo ato de crer, pois como vimos, pode ser apenas criticável, mas não culpável. Mas epistemicamente incorreto porque vícios epistêmicos obstruem a obtenção, manutenção e compartilhamento de conhecimento de forma sistemática e refletem negativamente as pessoas portadoras de tais vícios como o tipo de pensadores e conhecedores que estas pessoas são. E claramente pessoas portadoras de vícios intelectuais, nos contextos em que os vícios atuam não são bons informantes ou boas fontes de informação ${ }^{14}$. Vejamos agora como utilizar esta noção de vício epistêmico para avaliar os casos atuais da distribuição e crença em fake news nas redes sociais.

\section{Responsabilidade e fake news - estudo de caso}

Como avaliar os casos considerados atualmente problemáticos que envolvem a crença e compartilhamento de fake news? Primeiramente, é importante definir o que significa fake news, pois a forma popular do uso deste termo se refere a diversos tipos de eventos epistêmicos. Talvez um bom começo seja analisar como o dicionário Oxford, que em 2016 definiu o termo "pós-verdade" como a palavra do ano, define fake news: "histórias falsas que parecem ser notícias, espalhadas na internet ou através de outros meios, usualmente criadas para influenciar visões políticas ou como piadas" (OXFORD, 2020). Fake news, portanto, são parte de estratégias de manipulação políticas onde se distribui histórias falsas como se fossem notícias. Este tipo de manipulação não é algo recente. Desde que existe imprensa e jornalismo que vemos partidos políticos ou governos projetando notícias falsas para influenciar de modo enviesado as visões políticas.

\footnotetext{
${ }^{14}$ Edward Craig (1990) desenvolveu um argumento genealógico sobre a função do conceito de conhecimento, chegando à conclusão de que possuímos este conceito porque ele serve coo um indicador de boas fontes de informação e de bons informantes. Acredito que esta ideia torna ainda mais explícita a razão pela qual é epistemicamente incorreto crer de maneira epistemicamente viciosa.
} 
Porém, o termo fake news acabou por se popularizar nos últimos anos por ser parte de um tipo de estratégia de manipulação mais recente, a chamada Propaganda Computacional. De acordo com Woolley e Howard:

Propaganda computacional é um termo que resume claramente esse fenômeno recente - um campo de estudo emergente - de desinformação e manipulação digital. Como prática comunicativa, a propaganda computacional descreve o uso de algoritmos, automação e curadoria humana para gerenciar e distribuir totalmente informações enganosas por meio de redes de mídia social $(2019$, p. 4).

A propaganda computacional envolve a produção, gerenciamento e distribuição de notícias falsas (fake news), desinformação, mentiras, etc. Cada estratégia possui uma característica distinta. Por exemplo, a estratégia de desinformação não é a mesma que a de fake news: um governo pode desinformar a população ao esconder por exemplo fatos. Se o governo sabe que membros de sua equipe estão desviando dinheiro público, e ainda assim não fazem nada e ocultam estes fatos, temos um exemplo de desinformação. Claro, o governo pode utilizar-se também do recurso das fake news para criar notícias falsas de que todos os casos suspeitos de corrupção são devidamente investigados e punidos. Neste caso, o governo está claramente mentindo sob a aparência de notícias para desinformar e manipular a crença de sua população.

Além da mentira através das fake news e da desinformação, a estratégia de propaganda computacional pode utilizar como mecanismo de manipulação aquilo que Harry Frankfurt chamou de "falação de merda". A falação de merda é diferente da mentira no seguinte sentido:

É impossível mentir a menos que se pense que se sabe e verdade [...] Uma pessoa que mente responde por isso à verdade e nessa medida respeita-a. Quando um homem honesto fala, só diz o que pensa que é verdadeiro; e para o mentiroso é paralelamente indispensável que considere que as suas afirmações são falsas. Para quem fala merda, porém, não há quaisquer garantias de coisa alguma: não está do lado do verdadeiro nem do falso. Não tem de modo algum o olho nos factos, como acontece com o homem honesto e com o mentiroso, exceto na exata medida em que forem pertinentes para o seu interesse em safar-se com o que diz. Não se importa se as coisas que diz descrevem ou não a realidade corretamente. (FRANKFURT, 2005, pp. 55-56) 
Quando um governante ou um político mente, e através de sua estratégia de propaganda política manipula as pessoas, ele tem consciência de que está mentindo, e de que a suposta notícia é na verdade uma notícia falsa. Porém, quando há a falação de merda, nos termos de Frankfurt, o dito político não possui nenhum interesse pela verdade. Ou seja, não tem nem mesmo consciência se o que diz é verdadeiro ou falso. Não importa, para esta pessoa. A falação de merda serve mais para se ajudar a criar e manter uma narrativa (que pode ser verdadeira ou falsa) que é útil para o político, partido ou governante em questão. Por isso, assim como falação de merda é distinta da mentira, a mesma também é distinta das fake news.

O que todos estes elementos que são utilizados para estratégias de propaganda computacional possuem em comum é que são elementos epistemicamente nocivos. E são em geral distribuídos massivamente através da manipulação de algoritmos, automação e publicidade direcionada com o objetivo de poluir nosso ambiente informacional. Talvez por esta razão, muitos acabam chamando todos estes elementos de fake news, assim como chamamos muitas coisas diferente de poluição, seja fumaça no ar, seja plástico no mar. Para a nossa análise em questão, irei considerar fake news em seu sentido mais estrito de informação falsa que possui a aparência de uma notícia.

As fake news podem possuir diversos formatos: pode ter o formato de uma notícia em um site que aparenta ser um site jornalístico, mas é apenas de propagação de falsas notícias e outros elementos de propaganda computacional; com o formato de um áudio de alguma suposta autoridade transmitidas pelas redes sociais; como um texto que tem a aparência de um texto feito para noticiar algo e é transmitido pelas redes sociais, correio eletrônico e postado nos supostos sites de notícia; e como imagens ou vídeos com a aparência de ser um conteúdo informativo. Estas não são as únicas formas possíveis de descrever a anatomia das fake news. Há também o formato de boato. $\mathrm{O}$ formato de boato é aquele texto escrito em primeira pessoa onde o autor da mensagem conhece alguém que fez algo importante, por exemplo. O formato de boato não deve ser classificado estritamente como fake news, por ser outro elemento das estratégias de propaganda computacional que possui seus mecanismos próprios, mas para os propósitos deste artigo, não há problema em classificá-los como fake news. 
Além dos seus diversos formatos, as fake news são parte de toda uma estrutura de propaganda computacional que envolve a criação da mesma, a distribuição massiva por meio de algoritmos, automação, distribuição em grupos de WhatsApp e outras redes sociais, até, por fim, chegar ao usuário final, o usuário consumidor, que igualmente passa a distribuir dentro de seus círculos sociais. Dentro desta estrutura, encontraremos diversos graus de responsabilidades (epistêmicas e morais) por parte dos diversos atores envolvidos, sejam os produtores das fake news, as empresas contratadas para executar a estratégia, os contratantes e o usuário final, o público geral que consome as falsidades.

Qual tipo de responsabilidade, portanto possuem os produtores das fake news, as empresas contratadas que executam a estratégia de distribuição e os contratantes? Todos estes sabem que estão poluindo o ambiente informacional com informação nociva. Todos eles sabem que as informações por eles produzidas não tem a pretensão de serem verdadeiras. Desse modo, pode-se dizer que há, em todos eles, certo desprezo pela verdade. Esse é o vício que Cassam chama de malevolência epistêmica (2019, p. 87; 2018). Assim como a malevolência moral é uma oposição ao bem, a malevolência epistêmica faz oposição direta com o conhecimento. O exemplo usado para descrever um caso de malevolência epistêmica é a conhecida estratégia do tabaco, ${ }^{15}$ que tem muitas semelhanças com o caso que queremos analisar, da responsabilidade dos atores envolvidos nas fake news.

A indústria do tabaco, durante a década de 1950, fez uma série de descobertas científicas sobre o efeito do tabaco no fumante: o uso do tabaco causava câncer de pulmão e doenças cardiovasculares nos fumantes. Mas eles não podiam informar ao público em geral estas descobertas, pois evidentemente teriam prejuízos milionários pela queda da venda e consumo de seus produtos. Para contornar a situação, eles passaram a contratar profissionais de relações públicas e até mesmo cientistas para aparecerem em público colocando em dúvida a possibilidade de o tabaco causar câncer e outras doenças. Eles simplesmente estavam ativamente e voluntariamente se opondo a verdade. Eles estavam publicamente mentindo, poluindo o ambiente infor-

${ }^{15}$ Para uma compreensão mais completa da estratégia do tabaco e como ela foi usada também por outras indústrias, como a das bebidas açucaradas e dos medicamentos, ver Oreskes e Conway (2010). 
macional com informações nocivas que geravam dúvida nas pessoas e as impediam de obter conhecimento. Dada as condições de vícios epistêmicos, todos os envolvidos na estratégia do tabaco podem ser considerados epistemicamente culpados por este vício. Mas não somente epistemicamente, como moralmente, visto que como resultado de mais de 50 anos de estratégia, diversas pessoas contraíram câncer e diversas outras doenças como consequência do uso do tabaco, e muitas possivelmente morreram.

A estratégia que envolve a produção e distribuição massiva de fake news se assemelha muito a estratégia do tabaco. Sobre a estratégia do tabaco, Cassam afirma que "eles estão no negócio de ativamente minar o que, em privado, eles reconhecem como boas evidências em favor das teses que eles querem minar" (2019, p. 91). A estratégia de propaganda computacional que envolve fake news encontra-se exatamente no mesmo negócio: de ativamente minar tudo o que eles consideram boas evidências a favor das teses que eles atacam. Por isso a necessidade de gerar falsidades que simulem verdades ou notícias verdadeiras, para poluir completamente o ambiente informacional e evitar que as pessoas possam obter conhecimento. Assim como a estratégia do tabaco envolvia também malevolência moral, podemos supor que na estratégia das fake news há também culpa moral. Afinal, como vimos no início deste texto, este tipo de estratégia tem o poder de destruir vidas e carreiras de pessoas, proporcionando linchamento público por exemplo.

Mas como avaliar as pessoas que são ao mesmo tempo vítimas da estratégia das fake news como também parte da mesma, pois acabam acreditando e compartilhando as mesmas com a intenção de fazer com que outras pessoas também acreditem e compartilhem? Esse é um ponto de diferença entre a estratégia do tabaco e a das fake news: na estratégia do tabaco, as pessoas não eram parte ativa da estratégia, apenas vítimas. Não podemos dizer que elas eram responsáveis epistemicamente por crer ou suspender o juízo sobre as consequências do tabaco. Afinal, elas estavam usando talvez os melhores critérios para encontrar a verdade. Estavam escutando autoridades, cientistas, discutindo sobre o tema e não conseguiam formar uma crença adequada por não compreender as tecnicalidades levantadas nos debates (o que era parte da estratégia). Elas estavam dentro de um ambiente epistemi- 
camente poluído sem saber disso. Elas não tinham, portanto, nenhum tipo de responsabilidade de aquisição nem de revisão, e muito menos as falsas crenças formadas nelas refletiam negativamente em quem elas eram, e portanto, não poderiam ser criticadas por crer da forma que acreditavam.

Será que podemos afirmar o mesmo para as pessoas que consomem e distribuem fake news sem saber que estão fazendo parte de uma estratégia de poluição do ambiente informacional? A primeira pergunta que devemos fazer é se estas pessoas possuem ou responsabilidade de aquisição ou de revisão. E neste caso, a resposta é sim. Se fala atualmente de fake news em redes sociais, na grande imprensa, nas universidades e escolas. Todos sabem que o ambiente das redes sociais é altamente poluído. Isso exige que as pessoas tenham a obrigação epistêmica de verificar ou questionar a informação, antes de acreditar nas coisas que surgem por estes meios, mesmo que tenha sido compartilhado por pessoas de confiança. Alguém poderia questionar essa atribuição de responsabilidade, sob a argumentação de que a pessoa não sabia que estava ocorrendo em um vício epistêmico. Neste caso, seria a ignorância uma desculpa? Cassam responde que se a pessoa tem excelente evidências de que ela está pensando de forma viciosa (de que o ambiente informacional está poluído, de que existem muitas falsidades na rede, e de que não deveria aceitar sem questionar o que lhe aparece), mas ainda assim ela se recusa a acreditar que ela pensa de forma viciosa, porque ela se considera uma pessoa inteligente e virtuosa intelectualmente, então ela é responsável e culpada por sua ignorância (CASSAM, 2019, p. 129). Portanto, ela pode sim ser considerada responsável e culpada pelo vício epistêmico que ela possui.

O vício epistêmico provavelmente em jogo nestes casos é o da credulidade e possivelmente o da arrogância, quando a pessoa acredita que não é vítima de uma estratégia de fake news por ser inteligente e virtuosa. Ao contrário da malevolência epistêmica, que em geral anda lado a lado com a malevolência moral, não vemos aqui uma relação de implicação ou responsabilidade moral pela credulidade e/ou arrogância epistêmica. Porém, estas mesmas pessoas que recebem as fake news também compartilham. Qual a responsabilidade (epistêmica e moral) envolvida no ato de compartilhar as fake news, sem saber que elas são falsas? Estas pessoas que compartilham 
estas notícias em grupos de WhatsApp ou outras redes sociais o fazem porque muito provavelmente honestamente acreditam na verdade das informações compartilhadas.

Além de acreditar honestamente na verdade das informações, há uma questão ainda mais difícil de ser resolvida: o que estamos fazendo quando compartilhamos algo nas redes sociais? Duas possíveis respostas são analisadas por Masili (2020). Uma das hipóteses é a de que quando compartilhamos, estamos endossando o conteúdo compartilhado. E a segunda é a de que quando compartilhamos algo, estamos apenas citando o conteúdo compartilhado, sem necessariamente estar endorsando. Simplesmente compartilho o conteúdo na intenção de que outra pessoa veja o que eu vi e faça por ela mesma as avaliações que ela deve fazer. Não parece ser à toa que, como descreve Masili (2020, p. 8), muitos jornalistas acabam adicionando na seção de biografia de suas contas de Twitter que "um retweet não é um endosso". Isso porque muitos deles quere compartilhar as informações apenas para que outras pessoas saibam que tais informações existem, e não porque elas endossam as mesmas.

Ao argumentar que o ato de compartilhar nas redes sociais ${ }^{16}$ não equivale a endossar, mas sim, a um ato de citar o conteúdo, Masili busca analisar qual responsabilidade há nestes atos. No caso de uma pessoa que compartilha um conteúdo que sabe ser falso, "a responsabilidade moral e epistêmica de um enganador retweeter é equivalente ao de um enganador que tenta enganar sem mentir" (MASILI, 2020, p. 21). Também podemos afirmar que há responsabilidade moral quando o conteúdo compartilhado é diretamente nocivo para certas pessoas, como fotos inapropriadas, atos criminosos como calúnias e difamações, etc. Há responsabilidade moral em se compartilhar este tipo de conteúdo, mesmo que não seja equivalente a um endosso. Porém, nos casos das fake news, a pessoa que compartilha não se comporta como o enganador descrito por Masili e nem está compartilhando um conteúdo diretamente nocivo a uma pessoa (em geral, pois caso a fake news envolva um conteúdo criminoso, como calúnia a outra pessoa, falsa acusação de crime, por exemplo, a responsabilidade moral muda). Neste

\footnotetext{
${ }^{16}$ Apesar do foco de Masili ser o Twitter, ela afirma que sua análise pode ser facilmente generalizada para comportamentos similares em outras redes sociais (2020, p. 3 ).
} 
caso específico, não parece existir nenhum caso de responsabilidade moral envolvida no ato de compartilhar fake news, apenas a culpa epistêmica por crer de modo vicioso e por contribuir negativamente para a poluição do ambiente informacional.

Com base nesta discussão, poderíamos brevemente tentar formular algumas normas epistêmicas para o uso das redes sociais. E talvez a melhor sugestão venha de Clifford, quando ele fala a respeito do testemunho. Como temos consciência de que o ambiente das redes sociais é um ambiente repleto de conteúdos nocivos, não basta que a pessoa que nos envie a informação seja uma autoridade para simplesmente aceitar e acreditar a informação. Não basta para que a informação tenha a aparência e autoridade de uma notícia real para simplesmente acreditar na informação. Devemos buscar avaliar as virtudes epistêmicas das pessoas em nosso círculo, investigando se a pessoa tem o costume de crer de modo vicioso, tem o costume de compartilhar fake news e boatos e buscar compreender o que ela está fazendo ao compartilhar (se de fato está endossando ou apenas citando e quais razões motivam este comportamento). Neste aspecto, as ideias de Clifford caem como uma luva: "A bondade e a grandeza de um homem não nos dão justificação para aceitar uma crença com base na sua autoridade, a menos que haja uma base razoável para supor que conhece a verdade daquilo que afirma" (CLIFFORD, 2010, p. 120).

Alguém pode sugerir que há um alto custo cognitivo para seguir esta norma. De fato, há, mas por outro lado, é possível sugerir que este custo é ilusório. $\mathrm{O}$ custo parece ser alto porque a quantidade de informação que recebemos diariamente é altíssima. Vivemos sob um bombardeio constante de informação e seria inviável seguir esta norma para todas as informações que recebemos. Entretanto, será que necessitamos de fato tentar conhecer tudo o que está disponível diariamente? Afinal, se todos estão falando e discutindo sobre diversos temas neste momento, é porque estes temas são importantes, e eu devo saber. Mas a realidade é que não é bem assim. Quando o psicólogo Barry Schwartz (2004) descreve o que ele chama de Paradoxo da Escolha, ele apresenta um quadro onde quanto mais opções temos disponíveis para algo, mais dificuldade temos em escolher. A grande disponibilidade de opções nos paralisa e perdemos nossa capacidade de sermos livres para es- 
colher. O mesmo ocorre com a grande disponibilidade de informação: nós ficamos de certo modo epistemicamente paralisados, pois isso nos tira a capacidade de agirmos de forma epistemicamente virtuosa. Se torna fundamental certa abstinência midiática. Devemos aceitar que não temos a obrigação de saber tudo. E que devemos ser responsáveis com as informações que nos chega, aplicando a norma de Clifford no que diz respeito a aceitar o testemunho de outros via redes sociais.

Por fim, gostaria de chamar a atenção para o fato de que esta discussão demonstra a grande dificuldade que é a de se criar qualquer tipo de legislação que busque combater e penalizar fake news sem antes passar por análises cuidadosas e aprofundadas sobre o significado dos nossos atos nas redes sociais e as possíveis responsabilidades envolvidas. Uma legislação inadequada poderá ser um grande passo para qualquer tipo de totalitarismo, e não é isso que desejamos. Assim como atualmente pode ser difícil encontrar o real significado de atos como o de compartilhar, é possível que amanhã novas funcionalidades de interação com o conteúdo entrem em vigor, novas funcionalidades implicando novos atos públicos e talvez novas possíveis responsabilidades.

Talvez seja o caso de atualizar as leis existentes para pontualmente regular certos atos, como o da produção massiva e indústria de notícias falsas. E se já temos leis que criminalizam calúnias e difamação, talvez bastaria apenas discutir a aplicação das leis com base nas novas tecnologias. Mas não deveríamos considerar um crime compartilhara uma falsidade sem saber que é uma falsidade por exemplo. Por isso concluo destacando que a filosofia possui um papel fundamental nesta discussão e pode contribuir com o debate público, político e jurídico acerca das fake news e acerca de como avaliar adequadamente, epistemicamente e moralmente, nossas ações.

\section{Referências Bibliográficas}

BATTALY, Heather. Epistemic Virtue and Vice: Reliabilism, Responsibilism, and Personalism, In MI, Chienkuo; SLOTE, Michael e SOSA, Ernest (eds). Moral and Intellectual Virtues in Western and Chinese Philosophy. New York: Routledge. 2016. 
CASSAM, Quassim. Epistemic Insouciance. Journal of Philosophical Research, v. 43. 2018.

CASSAM, Quassim. Vices of the Mind: from the intellectual to the political. Oxford: Oxford University Press. 2019.

CLIFFORD, William. A Ética da Crença. In MURCHO, D. (ed.). A Ética da Crença. Lisboa: Editora Bizâncio. 2010.

COUTINHO, Emílio. Escola Base: Onde e como estão os protagonistas do maior crime da imprensa brasileira. São Paulo: Editora Casa Flutuante. 2016.

CRAIG, Edward. Knowledge and the state of nature: an essay in conceptual synthesis. Oxford: Claredon Press. 1990.

FRANKFURT, Harry. Sobre Falar Merda. Rio de Janeiro: Editora Intrínseca Ltda. 2005.

GRECO, John. Achieving Knowledge: A Virtue-theoretic Account of Epistemic Normativity. Cambridge: Cambridge University Press. 2010.

HAACK, Susan. 'The Ethics of Belief' Reconsidered. In STEUP, Matthias (ed). Knowledge, Truth, and Duty. Oxford: Oxford University Press. 2001.

KURZBAN, Robert. Why everyone (else) is a hypocrite. Evolution and the modular mind. Princenton: Princenton University Press. 2010.

MATTHESON, Jonathan; VITZ, Rico. The Ethics of Belief. Oxford: Oxford University Press. 2014.

MARSILI, Neri. Retweeting: its linguistic and epistemic value. Synthese. Publicado online em 29 jun 2020.

ORESKES, Naomi; CONWAY, Erik. Merchants of Doubt: How a Handful of Scientists Obscured the Truth on Issues from Tobacco Smoke to Global Warming. New York: Bloomsbury Publishing. 2010.

OXFORD, Dicionário. 2020. Disponível em https://dictionary.cambridge.org/us/dictionary/english/fake-news. Acesso em 25 jun 2020.

PEELS, Rik. Perspectives on Ignorance from Moral and Social Philosophy. New York: Routledge. 2017.

SOSA, Ernest. Judgment and Agency, Oxford: Oxford University Press. 2015.

STEUP, Matthias (ed). Knowledge, Truth, and Duty. Oxford: Oxford University Press. 2001. 
Perspectiva Filosófica, vol. 46, n. 1, 2019

SCHWARTZ, Barry. O paradox da escolha: Por que menos é mais. São Paulo: Editora a Girafa. 2004.

WOOLLEY, Samuel C.; HOWARD, Philip N. Computational Propaganda: political parties, politicians, and political manipulation on social media. Oxford: Oxford University Press. 2019.

ZAGZEBSKI, Linda. Virtues of the Mind: An Inquiry into the Nature of Virtue and the Ethical Foundations of Knowledge. Cambridge: Cambridge University Press. 1996. 